\title{
Nachruf
}

\section{Prof. Dr. Seraina Plotke †}

18.07.1972-27.10.2020

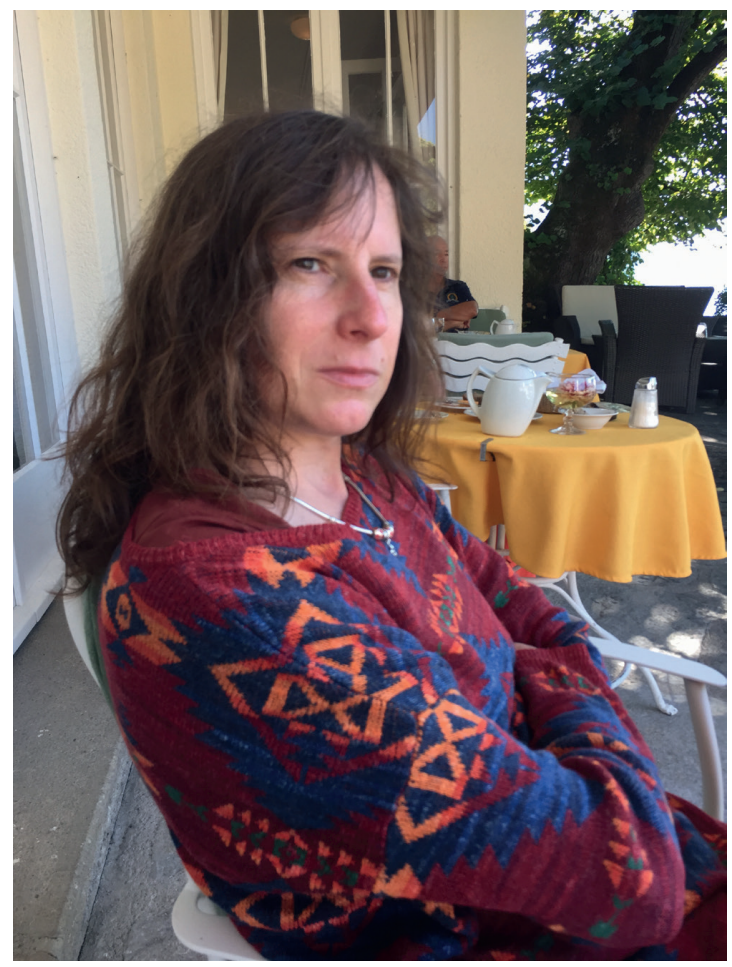

Seraina Plotke studierte von 1992 bis 1999 Germanistik, Latinistik und Philosophie an der Universität Basel, an der sie zwanzig weitere Jahre mit vorbildlichem Engagement in Forschung und Lehre, Betreuung und Selbstverwaltung wirkte und eine beeindruckende wissenschaftliche Schaffenskraft entfaltete. Nach einem Forschungssemester an der University of Wisconsin-Madison 
war Seraina Plotke als wissenschaftliche Mitarbeiterin zunächst in dem interdisziplinären SNF-Forschungsprojekt Zivilisationstheorie, Diskursanalyse, Geschlechtergeschichte. Mittelalterliche Erziehungsschriften für rechtes Verhalten im Kloster, am Hof und im städtischen Milieu und anschließend in dem buch- und mediengeschichtlichen Projekt Opera poetica Basiliensia an der Universität Basel tätig.

Promoviert wurde Seraina Plotke 2005 mit der Studie Gereimte Bilder. Visuelle Poesie im 17.Jahrhundert (erschienen 2009). Die Gattungsmonographie bezeugt zugleich das Interesse ihrer Verfasserin an systematisch-literaturtheoretischen Fragen wie auch ihre Fähigkeit zu umfassender historischer Erschließung eines Gegenstands unter selbstverständlichem Rückgriff auf die lateinische Tradition, wobei sie beides in äußerst geraffter Darstellung zu verbinden wusste. Seraina Plotke begreift die Figurengedichte des Barockzeitalters in zeichentheoretischer Hinsicht als Einheit von Text und Bild, und untersucht sie zugleich in ideengeschichtlicher Perspektive, indem der Hintergrund mittelalterlicher Allegorese, frühneuzeitlicher Sprachphilosophie und Poetik, besonders der Horaz-Rezeption (ut pictura poesis) oder der entstehenden Emblematik diskutiert wird. Diese Perspektiven werden jeweils durch genaue Einzelinterpretationen (von Figurengedichten Sigmund von Birkens, Johann Klajs, Theodor Kornfelds oder Johann Geuders) anschaulich gemacht.

Nachdem bereits die Dissertation die frühneuzeitliche Emblematik als enge Parallele zur visuellen Poesie einbezogen hatte, widmete sich Seraina Plotke in mehreren weiteren Beiträgen dieser bimedialen Gattung, wobei ihr besonderes Interesse auf den Frühformen und Vorläufern, etwa den Bezügen zur antiken Epigrammatik, auf Andrea Alciati oder seinen frühen deutschen Übersetzern lag und die Gattung so als Ergebnis des medialen "Experimentierfelds", die der frühe Buchdruck war, verstehbar wurde. Folgerichtig engagierte sich Seraina Plotke in der Society for Emblem Studies an verantwortlicher Stelle. Auch ihre Edition der Vita Beati des Daniel Agricola von 1511, die nichtlateinkundigen Lesenden dank einer synoptisch gebotenen Übersetzung einen neuen Zugang zu der frühsten Bearbeitung der Legende des "Apostels der Schweiz" ermöglicht, ist in diesem Kontext zu erwähnen. Treffend charakterisierte Seraina Plotke den Basler Frühdruck aufgrund der annähernd zwanzig Holzschnitte des Renaissance-Künstlers Urs Graf als "Emblembuch avant la lettre".

Von 2005 bis 2012 war Seraina Plotke als wissenschaftliche Assistentin in der Germanistischen Mediävistik der Universität Basel und zeitweilig zusätzlich an der Albert-Ludwigs-Universität in Freiburg/Breisgau tätig. Darüber hinaus übernahm sie Lehraufträge am Seminar für Klassische Philologie bzw. am Departement Altertumswissenschaften der Universität Basel, weshalb ihre doppelte Venia - sowohl in Deutscher Literatur des Mittelalters und der 
Frühen Neuzeit als auch in Neulatein - als eine logische Folge ihrer langjährigen Lehr- und Forschungstätigkeit erscheint. Nach ihrer Habilitation 2012 wurde sie zur Hochschuldozentin für Germanistische Mediävistik an der Universität Basel ernannt, zwischenzeitlich führten sie ein Erasmus Mundus Scholarship GLITEMA an die Universität Bremen und eine Gastprofessur am Graduiertenkolleg Interkonfessionalität in der Frühen Neuzeit an die Universität Hamburg. Als Mitglied des interdisziplinären wissenschaftlichen DFG-Netzwerks Humanistische Antikenrezeption und frühneuzeitliche Poetik in Deutschland (1480-1620) trug Seraina Plotke dazu bei, den Einfluss der volkssprachigen Übersetzungskultur auf die Entwicklung der deutschen Sprache und Literatur in der Frühen Neuzeit neu zu bestimmen; seit 2018 gehörte sie dem Editorial Board von Daphnis an.

Zu ihren Forschungsschwerpunkten zählten neben der Buch- und Mediengeschichte und der Antikenrezeption auch die Historische Semantik, die Narratologie und die Gender Studies. Ihr 2008 erschienener gehaltvoller Aufsatz zur Wort- und Begriffsgeschichte der Conversatio/Konversation wurde ins Englische übertragen und unter dem Titel Semantic Traces of Social Interaction from Antiquity to Early Modern Times als Monographie bei Cambridge Scholars Publishing 2017 verlegt. Diesem Ansatz ist auch der von ihr mitherausgegebene Sammelband Sprache der Trauer verpflichtet, der linguistische, literaturwissenschaftliche und philosophische Beiträge zu Beispielen von der Antike bis zur Gegenwart vereint.

Ebenfalls 2017 erschien ihre wichtige Studie Die Stimme des Erzählens, in der Seraina Plotke die Übertragbarkeit moderner narratologischer Kategorien auf die mittelalterliche Buchkultur grundlegend problematisiert. Sie legt offen, dass das immer wieder diskutierte Verhältnis von Autor und Erzähler unmittelbar mit dem Buchwesen zusammenhängt und die fehlende paratextuelle Rahmung in der mittelalterlichen Manuskriptkultur grundlegende Konsequenzen für die Konstituierung der Erzählinstanz in der höfischen Epik hat. Die volksprachige Autorschaft kollidiert mit der Kategorie der textvermittelnden Erzählinstanz, weil sie nur indirekt als Teil eines textinternen Kommunikationsverhältnisses zu greifen ist. Aufgrund dieser Beobachtung hält die Verfasserin die methodische Differenzierung zwischen gestalterischen Formelementen und Diskursfunktionen für fruchtbarer als die in der Literaturtheorie fixierte und auf mittelalterliche Texte projizierte Trennung von Autor und Erzähler. In fünf Analysekapiteln zum Herzog Ernst B, zum Eneasroman Heinrichs von Veldeke, Hartmanns von Aue Iwein, Wolframs von Eschenbach Willehalm und Rudolfs von Ems Alexander wird das Verhältnis von Gestaltungs- und Kommunikationsinstanz individuell bestimmt und die spezifische Medialität wie die typische Rezeptionssituation volkssprachiger 
Erzähltexte angemessen berücksichtigt. Den Gewinn einer solchen historisch sensibilisierten Narratologie stellte Seraina Plotke auch in zahlreichen weiteren Aufsätzen unter Beweis, in denen sie sich mit der Konstituierung von Erzählinstanzen, Fragen der Autorschaft und Autorität, unzuverlässigem Erzählen, Figurenkonzepten, Handlungsmotivation und Erzählperspektiven in der Literatur des Mittelalters und der Frühen Neuzeit widmete.

Im Rückblick erscheint das Jahr 2019 zugleich als beruflicher Höhepunkt und krönender Abschluss einer höchst erfolgreichen, aber viel zu früh endenden akademischen Vita: Seraina Plotke wurde als Professorin für Germanistische Mediävistik an die Otto-Friedrich-Universität Bamberg berufen, und sie übernahm die Leitung des Forschungsprojekts zu Sebastian Brantim Schnittfeld frühneuzeitlicher Textkulturen, dessen Finanzierung sie beim SNF eingeworben hatte. Mit diesem Projekt kehrte Seraina Plotke noch einmal zu jenen Themen zurück, die sie von Beginn ihrer Forschungstätigkeit an beschäftigt hatten und die sie nun gemeinsam mit ihren beiden wissenschaftlichen Mitarbeiterinnen erforschte: die Text-Bild-Konfigurationen, die medialen Besonderheiten des frühen Buchdrucks, der parallele Gebrauch von Latein und Volkssprache. Erweitert wurden diese kommunikations- und übersetzungsgeschichtlichen Perspektiven im Brant-Projekt jedoch auf innovative Weise durch gendertheoretische Ansätze, mit denen sich Seraina Plotke in den letzten Jahren in mehreren Forschungsbeiträgen intensiv auseinandergesetzt hatte. Vor allem an Orientdarstellungen arbeitete sie heraus, wie in der mittelalterlichen Erzählliteratur Freiräume jenseits etablierter heteronormativer und sanktionierter gesellschaftlicher Normen geschaffen und Geschichten über Hybridwesen und gleichgeschlechtliche Beziehungen mehrstimmig erzählt werden.

Neben der Erforschung der Genderkonzeption im Narrenschiff und der Erschließung der lateinischen Gedichte Sebastian Brants beschäftigten Seraina Plotke weitere Editionsprojekte, die sie nicht mehr zu Ende führen konnte. Schon lange hatte sie an einer Ausgabe und Übersetzung des lateinischen Herzog Ernst $C$ gearbeitet, die kurz vor der Fertigstellung stand, im Anschluss war eine Online-Edition von Konrads von Würzburg Partonopier und Meliur geplant. In Druckvorbereitung befinden sich auch zwei Sammelbände zu Nibelungendiskursen im Nationalsozialismus und zu De mulieribus claris, die Seraina Plotke mitherausgeben wollte, wie sie auch zu früheren Zeitpunkten ihrer Karriere interdisziplinäre Tagungen organisiert, Gäste großzügig umsorgt und wissenschaftliche Bände etwa zu Parodie und Verkehrung oder zu Schwanksammlungen im frühneuzeitlichen Medienumbruch verantwortungsbewusst betreut hatte. Bis wenige Tage vor ihrem Tod arbeitete sie ebenso unermüdlich wie motiviert an ihren Publikationsprojekten, soweit ihre schwere Krankheit ihr dies noch gestattete. 
Die germanistische Mediävistik verliert mit Seraina Plotke eine scharfsinnige, kluge, inspirierende und authentische Wissenschaftlerin, die sich beispielhaft für ihr Fach und für Studierende einsetzte, junge Forschende ermutigte und sich von strukturellen Zwängen und hierarchischen Hürden nicht schrecken ließ. Zweifellos werden ihre Projekte weiter wirken und ihre Publikationen insbesondere zur visuellen Poesie, zur mittelalterlichen und frühneuzeitlichen Buchkultur und zur Narratologie auch in Jahrzehnten noch rezipiert werden, doch als Kollegin, Lehrerin und Freundin ist sie mit all ihrer Leidenschaftlichkeit, Integrität, Authentizität und Begeisterungsfähigkeit unersetzlich. Wir vermissen sie sehr.

Johannes Klaus Kipf

München

Regina Toepfer

Braunschweig 